\title{
O DIREITO DO CONSUMIDOR E O TRATAMENTO JURÍDICO DADO À PUBLICIDADE DE PRODUTOS NANOESTRUTURADOS NA INTERNET: UM PANORAMA DO TEMA NO BRASIL E NA UNIÃO EUROPEIA
}

\author{
THE RIGHT OF CONSUMER AND TREATMENT GIVEN TO THE LEGAL \\ NANOSTRUCTURED PRODUCTS ADVERTISING ON THE INTERNET: A THEME \\ PANORAMA IN BRAZIL AND THE EUROPEAN UNION
}

\author{
${ }^{1}$ Rosane Leal Da Silva \\ ${ }^{2}$ Valdirene Silveira Flain
}

\section{RESUMO}

O presente trabalho tem por objetivo abordar, sob a égide do Direito do Consumidor, o tratamento jurídico da publicidade online de produtos que se utilizam da nanotecnologia no Brasil e na União Europeia. A difusão das vantagens e da eficiência desses produtos encontra nas Tecnologias da Informação e Comunicação (TIC), através da publicidade online, uma grande aliada, pois seu uso abre um importante canal que lhes permite estar em constante contato com seus consumidores, estimulando-os ao uso desses produtos, cujas vantagens são enaltecidas, sem que os potenciais riscos à saúde humana sejam suficientemente informados. Esse tema, apesar de relativamente novo no Brasil, já conta com debate mais amadurecido na União Europeia (UE), com estudos feitos pela NaNoREG, organização europeia responsável pela regulação e comercialização de nanomateriais, com a qual o Ministério da Ciência, Tecnologia e Inovação (MCTI) brasileiro tem feito contato no sentido de integrarse a um esforço de regulamentação mundial. Para tratar do tema, partiu-se de uma abordagem dialética, na qual foi feito o contraste entre vantagens e riscos advindos do dessa tecnologia, evidenciando as situações que os efeitos não são suficientemente esclarecidos ao consumidor. Partindo de exemplos de publicidade online, onde se evidencia o grande incentivo ao uso de nanocosméticos, foi abordada a necessária defesa da saúde e segurança do consumidor, contrastando a regulamentação existente na União Europeia e no Brasil.

Palavras-chave: Direito do consumidor, Nanotecnologia, Publicidade online, Regulação. união europeia

\footnotetext{
${ }^{1}$ Doutor em Direito pela Universidade Federal de Santa Catarina - UFSC, Santa Catarina (Brasil). Professor de Mestrado em Direito pela Universidade Federal de Santa Maria - UFSM, Rio Grande do Sul (Brasil). E-mail: rolealdasilva@gmail.com

${ }^{2}$ Mestranda em Direito pela Universidade Federal de Santa Maria - UFSM, Rio Grande do Sul (Brasil). E-mail: valflain@gmail.com
} 


\begin{abstract}
This paper aims to treat, under the aegis of the Consumer Law, the legal treatment of advertising online of products that use nanotechnology in Brazil and European Union. The spread of the benefits and efficiency of these products, has in the Information and Communication Technologies (ICT) a great ally, because through online advertising, opens an important channel that allows them to be in touch constant with its consumers, encouraging them the use of these products, whose advantages are praised, without that the potential risks to human health receives sufficient information. This theme, though relatively new in Brazil, has been more debated in the European Union (EU), to studies done by NaNoREG, European organization responsible for the regulation and commercialization of nanomaterials, with which the Ministry of Science, Technology and Innovation (MCTI) Brazilian has made contact to integrate to a global regulation effort. To treat the issue used a dialectical approach, was made the contrast between benefits and risks arising from this technology, pointing out situations in that effects are not sufficiently clear to the consumer. Starting to from online advertising examples that is evident the great incentive to use the nanocosmetics, and addressed the necessary protection of public health and consumer safety, contrasting the current rules in the European Union and in Brazil.
\end{abstract}

Keywords: Consumer law, Nanotechnology, Online advertising, Regulation, European union 


\section{INTRODUÇÃO}

O desenvolvimento das Tecnologias da Informação e Comunicação (TIC) alterou o panorama social, surgindo uma sociedade em rede, que também se caracteriza como uma sociedade de consumo globalizada, onde se recebe de maneira instantânea uma massa de informações e publicidades online sem um controle prévio, a partir de um sistema de mídia onipresente.

$\mathrm{O}$ advento das tecnologias da informação e seu crescente uso ampliaram as formas de manifestação da publicidade, que cada vez mais assume novos formatos e papeis, não apenas informando sobre a existência de um produto, mas atuando como uma ferramenta fundamental para despertar o desejo nos consumidores. Este novo formato não só aumenta o consumo levando ao consumismo, como também acirra ainda mais a concorrência entre as empresas, que a todo o momento são provocadas a reinventar sua publicidade.

A publicidade online é uma das formas dessa reinvenção e contornos bastante importantes, pois além de se misturar aos demais fluxos informacionais, muitas vezes sequer sendo percebida, ainda chega ao consumidor em qualquer tempo e lugar, o que lhe confere muito mais poder de penetração. E essas mensagens, no afã de incitar à compra dos produtos, muitas vezes descuidam-se do papel informativo, omitindo informações necessárias sobre a tecnologia utilizada e os possíveis riscos, o que fere o direito do consumidor.

Essas estratégias e riscos tem sido uma constante quando se trata de publicidade de produtos nanoestruturados, especialmente cosméticos, cuja oferta usualmente vem acompanhada de promessas de rápidos efeitos sem advertir dos possíveis riscos à saúde humana. De inquestionável importância à saúde do consumidor, este tema ainda tem sido pouco tratado no Brasil, situação que contrasta com a de outros países, como a União Europeia, bloco de Estados que tem investido em pesquisas para aprimorar ainda mais esses produtos e com isso alavancar sua economia.

É essa problemática que se aborda no presente trabalho, desenvolvido a partir da adoção do método de abordagem dialético empregado para fazer o contraste entre as vantagens advindas do uso dessa nova tecnologia com potenciais riscos que essas inovações podem produzir sobre a saúde dos consumidores. O método de procedimento eleito é o monográfico, empregado para selecionar publicidades na internet que bem evidenciassem o tema, levando em conta principalmente as mensagens online que estimulam o consumo de produtos desenvolvidos com nanotecnologia. Como técnica de pesquisa foi utilizada a análise bibliográfica, documental e de observação em publicidades divulgadas por meio da internet.

Revista de Direito, Glob e Res. nas Rel. de Cons.| e-ISSN: 2526-0030 | Minas Gerais | v. 1 | n. 2 | p. 1-26|Jul/Dez. 2015. 
Nesse sentido, ainda será feita uma sumariada observação direta de uma publicação sobre nanotecnologia, feita no site Bolsa de Mulher. O site Bolsa de Mulher é um dos sites do Grupo Bolsa de Mulher, propriedades digitais da empresa Batanga Media, fundada em 1999, sediada em Miami - Flórida - e tem operações em 14 países, incluindo Argentina, Brasil, Chile, Colômbia, México e Venezuela. A escolha da observação sobre a publicação do site Bolsa de Mulher se deu em função do seu alcance e popularidade, pois tal site atinge um amplo público digital, principalmente na América do Sul. O site Bolsa de Mulher tem como objetivo manter as mulheres sempre atualizadas sobre todos os assuntos que importam para o universo feminino, inclusive sobre a beleza e as inovações nos produtos desse segmento.

Dividiu-se o trabalho em quatro principais capítulos. Para uma melhor compreensão, no primeiro capítulo serão apresentadas algumas notas conceituais sobre nanotecnologia, assim como as vantagens e possíveis riscos derivados de seu uso. No segundo capítulo será feita uma abordagem sobre a publicidade na sociedade em rede, realçando os anúncios de produtos nanoestruturados que ganham espaço no ambiente virtual. No terceiro capítulo, será feita uma análise do uso da nanotecnologia no Brasil, que se destaca como líder em nanotecnologia na América Latina, apesar de não contar com efetiva regulação sobre o tema, conforme será demonstrado. Por derradeiro no quarto capítulo, será feita a abordagem sumariada do tratamento jurídico da nanotecnologia na União Europeia.

\section{NOTAS CONCEITUAIS PARA A COMPREENSÃO DA NANOTECNOLOGIA: ENTRE AS PROMETIDAS VANTAGENS E OS POTENCIAIS RISCOS.}

Quando se fala em nanotecnologia, pensa-se em uma tecnologia emergente, no entanto, ela já faz parte da vida e já causa grandes impactos no cotidiano das pessoas, apresentando-se como uma solução viável em vários setores da sociedade. Alves (2010, p.19), diz que foi Norio Taniguchi que, em 1957, cunhou o termo nanotecnologia, mas que significava, na época, apenas máquinas que tivessem níveis de tolerância inferiores a 1 mícron $(1.000 \mathrm{~nm})$.

O emprego dessa terminologia na acepção atual, no entanto, é mais recente. Segundo Alves (2010, p. 17) o termo pode ter surgido na década de 80, período histórico em que foi possível manipular isoladamente as partículas. O mesmo autor chama a atenção para outro aspecto bastante peculiar da nanotecnologia, que é a quebra de paradigma do tempo, que hoje, entre a pesquisa fundamental e a aplicação, é bem menor.

Revista de Direito, Glob e Res. nas Rel. de Cons. | e-ISSN: 2526-0030 | Minas Gerais | v. 1 | n. 2 | p. 1-26|Jul/Dez. 2015. 
Ao tratar do conceito do termo nanotecnologia, o Grupo ETC (GRUPO ETC, 2005, p.13) define como "[...] um conjunto de técnicas usadas para manipular a matéria na escala de átomos e moléculas". Desse conceito singelo denota-se que o prefixo "nano", refere-se a uma medida e não a um objeto.

E as explicações mais detalhadas também partem do Grupo ETC (2005, p. 13):

Diferente da "biotecnologia", onde se sabe que bios (vida) é manipulada, "nanotecnologia" refere-se somente à escala. Um "nanômetro" $(\mathrm{nm})$ equivale a um bilionésimo do metro. Um fio de cabelo humano tem aproximadamente $80 \mathrm{mil}$ nanômetros de espessura. São necessários dez átomos de hidrogênio lado a lado para se ter um nanômetro. Uma molécula de DNA tem aproximadamente $2,5 \mathrm{~nm}$ de largura. Um glóbulo vermelho, em comparação, é imenso: aproximadamente 5.000nm de diâmetro. Tudo em nanoescala é invisível ao olho nu e até mesmo a todo o resto, exceto a microscópios muito poderosos.

Ocorre que essa redução das medidas oferece potencial para desenvolvimento de outras transformações, como também se constata da leitura da mesma publicação do Grupo ETC (2005, p. 14):

Só reduzindo o tamanho, e sem mudar a substância, os materiais podem exibir novas propriedades tais como condutividade elétrica, elasticidade, maior resistência, cor diferente e maior reatividade - características que essas mesmas substâncias não exibem em escala micro ou macro. Por exemplo:

- Carbono na forma de grafite (como lápis) é macio e maleável; em nanoescala pode ser mais resistente do que o aço e seis vezes mais leve;

- O óxido de zinco é normalmente branco e opaco; em nanoescala se torna transparente.

- O alumínio - material utilizado nas latinhas de refrigerante - em nano escala pode entrar em combustão espontânea e poderia ser utilizado como combustível para foguetes.

Conforme Alves (2010, p.16), nessa escala de tamanho, as propriedades modificamse drasticamente, levando a caracterização de um universo muito particular, o que faz cunhar o termo nanotecnologia para identificá-lo.

Além da redução do tamanho, ainda merece atenção o fato de esses produtos, especialmente os cosméticos, utilizarem partículas lábeis e não-lábeis. Como exemplo das primeiras tem-se os lipossomas, que são as que se dissolvem física ou quimicamente em contato com a pele, enquanto as partículas não-lábeis são insolúveis, não se dissolvem em contato com a pele, a exemplo do fulereno e dos nanotubos de carbono, e podem se acumular em órgãos, causando toxicidade e possíveis riscos à saúde do consumidor (SCCP, 2007 apud FRONZA; GUTERRES; POHLMANN; TEIXEIRA, 2007, p.36). 
Como se percebe dessa rápida descrição, a nanotecnologia é o resultado e a aplicação da nanociência, através da manipulação da matéria em uma escala namométrica, o que transforma essa matéria, dando ensejo ao aparecimento de novos riscos, ainda não suficientemente esclarecidos pela comunidade científica.

Conforme a National Science Fondation, Estados Unidos (NNA, 2005 apud FRONZA; GUTERRES; POHLMANN; TEIXEIRA; 2007, p.35), a nanotecnologia causará, em 2015, um impacto na economia global de cerca de 1 trilhão de dólares e envolverá cerca de 2 milhões de trabalhadores. Tais estimativas atraem um crescente número de investimento global em nanotecnologia, em diferentes partes do mundo. Como exemplo, tem-se a Europa, que investiu, em 2004, 1 bilhão de euros; o Japão que, em 2001, inverteu 400 milhões de dólares, em 2003, o duplicou o investimento para 800 milhões e o Reino Unido, que aplicou 45 milhões de libras nesse segmento. No entanto, nenhum desses países superou os Estados Unidos que, de 2005 a 2008, aplicaram 3,7 bilhões de dólares no setor.

A nanotecnologia começou a tomar uma forma mais institucionalizada no Brasil a partir de 2001, quando o governo federal lançou o primeiro edital na área da Nanociência e da Nanotecnologia (NN) para formação de "redes cooperativas" (GRUPO ETC, 2005, p.7). Essas "redes cooperativas" demonstram, por meio de pesquisas, que a matéria exibe propriedades diferentes, ultrapassando as fronteiras entre as áreas técnico-científicas, o que resulta em um caráter interdisciplinar da nanotecnologia, oferecendo aplicações e possíveis soluções em várias áreas do conhecimento. Para exemplificar algumas áreas onde a nanociência e a nanotecnologia já encontram aplicação, tem-se a indústria têxtil, cosméticos, fármacos, medicina, computação e armazenamento de dados, energia, meio ambiente, transporte, segurança nacional, entre outras.

Pesquisadores atuantes na área veem na nanotecnologia o potencial para que doenças incuráveis sejam tratadas, materiais com propriedades excepcionais nunca observados sejam obtidos, gerando perspectivas de grandes mudanças sociais e econômicas (GRUPO ETC, 2005, p. 8).

A despeito da produção em segmentos variados, o maior apelo é na indústria de nanocosméticos, cujos anúncios mobilizam os sentidos e sentimentos de vaidade dos consumidores. Esse segmento destaca-se por apresentar produtos com novas fórmulas que prometem, através de estratégias de marketing, principalmente através da publicidade ${ }^{1}$ online, resultados rápidos de rejuvenescimento da pele e cabelos.

\footnotetext{
${ }^{1}$ Neste trabalho será empregado o conceito exposto por Cláudia Lima Marques (1999, p. 673), para quem
} "Publicidade é toda a informação ou comunicação difundida com o fim direto ou indireto de promover junto aos 
Hoje, a nanotecnologia é uma realidade na indústria mundial, sendo a indústria brasileira líder no mercado de produtos nano na América Latina, aplicando esse conhecimento para desenvolver novos e eficientes produtos, oferecendo importantes soluções nas mais variadas áreas do conhecimento.

No entanto, a nanotecnologia não oferece somente benefícios, pois Engelmann, Flores e Weyrmüller (2010, p.17), advertem que um primeiro limite para pesquisa em nanoescala seria que os pesquisadores operariam combinações que não se deixariam mais controlar devido à complexificação das combinações dos átomos. Esses mesmos autores alertam que ainda se desconhecem as repercussões que essas pesquisas gerarão na natureza e os modos como elas atingirão a vida humana no planeta, pois "as novas possibilidades de combinação, poderão liberar substâncias e produzir resíduos de difícil controle" (ENGELMANN, FLORES; WEYRMÜLLER, 2010, p. 18).

Na mesma esteira de raciocínio o Grupo ETC (2005, p. 40) também adverte:

Ao permitir que produtos da nanotecnologia cheguem ao mercado na ausência de um debate público e sem regulamentação, os governos, o agronegócio e as instituições científicas já comprometeram os benefícios potenciais das tecnologias nanoscópicas. Antes de tudo, é a sociedade - incluindo agricultores, organizações da sociedade civil e movimentos sociais - que devem empreender um amplo debate em torno da nanotecnologia e suas múltiplas implicações econômicas, de saúde e ambientais. Invocando o Princípio da Precaução, todos os produtos alimentares, para rações e para bebidas (inclusive suplementos nutricionais) que contiverem nanopartículas fabricadas devem ser removidos das prateleiras. Também deve ser proibida a comercialização de novos, até o momento que entrem em vigor os protocolos laboratoriais e as normas de regulamentação que levem em conta a característica especial desses materiais, e até que se demonstre que tais produtos são seguros. Da mesma forma, deve ser proibida a liberação no ambiente das formulações em escala nanométrica de produtos agrícolas, como agrotóxicos e fertilizantes e para tratamento do solo, até que novos regimes de regulamentação especificamente destinados a examinar tais produtos os consideram seguros.

Pode-se perceber, também, que Fronza, Guterres, Pohlmann e Teixeira (2007, p.35), quando tratam da "Segurança de Uso de Nanocosméticos", demonstram preocupação em função de crescente acesso da população a uma diversidade de produtos cosméticos de base nanotecnológica. Os autores reforçam essa preocupação, mencionando que "[...] diversas organizações têm demonstrado preocupação quanto à segurança de uso dos nanocosméticos uma vez que esta pode diferir dos cosméticos convencionais em decorrência do reduzido diâmetro das estruturas".

consumidores a aquisição de um produto ou serviço, qualquer que seja o local ou meio de comunicação utilizado". 
A principal preocupação é com as partículas insolúveis, tendo em vista que elas não são eliminadas, podendo ocorrer seu eventual acúmulo em diferentes órgãos, como exemplo o fígado, pulmões e rins. Apesar de a preocupação com essas partículas ser mais evidente, também não existem testes que comprovem que as partículas solúveis, as que se dissolvem em contato com a pele, não causam nenhum dano ao organismo humano (SCCP, 2007 apud FRONZA; GUTERRES; POHLMANN; TEIXEIRA, 2007, p.37).

No próximo capítulo, será feita uma abordagem de forma sucinta sobre as estratégias de marketing na publicidade online dos produtos nano, utilizadas pela indústria como ferramenta para persuadir o consumidor a comprar seus produtos.

\section{A PUBLICIDADE NA SOCIEDADE EM REDE: OS ANÚNCIOS DE PRODUTOS NANOESTRUTURADOS GANHAM ESPAÇO NO AMBIENTE VIRTUAL.}

$\mathrm{O}$ advento da internet e a crescente utilização das Tecnologias de Informação e Comunicação (TIC), a despeito de permitirem um amplo acesso, têm produzido profundas transformações sociais. Por intermédio de uma mídia onipresente tem impactando vários setores da sociedade, tornando-a em rede e insuflando complexidades jamais imaginadas, $\mathrm{o}$ que desafia a sociedade e o Estado com novas demandas.

Manuel Castells (1999, p.17) refere que a revolução da tecnologia da informação e a reestruturação do capitalismo introduziram uma nova forma de sociedade que é caracterizada pela globalização das atividades econômicas, organização em redes, flexibilidade, instabilidade do emprego e a individualização da mão de obra. Essa verdadeira revolução da tecnologia da informação colaborou nas duas últimas décadas para o surgimento de um novo modelo de economia, uma economia informacional e de fluxos, que não encontra limites temporais ou espaciais, pois todo o tempo passa a ser propício para o consumo.

Parafraseando Bauman (1999, p. 86), pode-se dizer que a indústria atual funciona cada vez mais para produção de atrações e tentações, para que os consumidores experimentem sensações novas, ainda não experimentadas e colecionem coisas, ainda que num sentido secundário e derivativo. Assim, o advento da internet e a larga utilização das TIC, facilitam muito a divulgação dos produtos, servindo como uma poderosa ferramenta para uma indústria que tem como objetivo aumentar seus lucros com as vendas dos seus produtos, pois através da publicidade ${ }^{2}$ online pode atingir direta e rapidamente milhares de consumidores.

\footnotetext{
${ }^{2}$ Importante fazer uma distinção entre publicidade e propaganda. Propaganda não se confunde com publicidade, na medida em que o primeiro conceito significa disseminar uma ideia ou uma crença (de sentido religioso ou
}

Revista de Direito, Glob e Res. nas Rel. de Cons.| e-ISSN: 2526-0030 | Minas Gerais | v. 1 | n. 2 | p. 1-26|Jul/Dez. 2015. 
A incontrolável penetração da publicidade no ambiente virtual não surpreende autores como Jean Jacques Erenberg (2003, p. 37), para quem "era evidente que assim que deixasse de existir a vedação ao uso comercial da internet, seria uma questão de tempo para que a publicidade invadisse e dominasse a rede mundial de computadores". Ainda conforme este autor (2003, p.38):

Em 1993, quando caíram as restrições comerciais e a Wold Wide Web se tornou acessível ao público, surgiu a primeira publicação comercial on-line, a GNN. Outros sites pioneiros se seguiram, tendo como anunciantes empresas de tecnologia como a Microsoft e a MCI. Até então não surgiam maiores problemas, vez que somente eram expostos à publicidade aqueles que optavam por digitar o endereço eletrônico de uma dessas publicações, sabidamente comerciais.

Conforme Dias (2010, p.22), a publicidade tem um objetivo econômico e a sua finalidade é estimular as vendas ou criar certo estilo de vida por meio da difusão e enaltecimento das qualidades de um produto ou serviço. Nesse contexto a publicidade online potencializa esses estímulos, pois com o uso de TIC as mensagens chegam facilmente ao consumidor, divulgando-se uma infinidade de produtos e serviços de toda ordem, com o objetivo de informar sua existência e persuadir ao consumo.

Como se sabe, a publicidade tem o poder de mudar os costumes no vestir, comer, comportar-se e até pode servir de instrumento de um colonialismo econômico ou cultural, como sustentado por Nalini (2009, p. 260-261), ao dizer que quem habita a sociedade de consumo está subordinado aos comandos da publicidade. Principalmente quando essa sociedade de consumo é também uma sociedade em rede, sob o impacto das TIC, onde se recebe todo tipo de informações de forma simultânea.

Corroborando esse entendimento, Bauman (1998, p.55) sustenta que:

O consumo abundante, é-lhes dito e mostrado, é a marca do sucesso e a estrada que conduz diretamente ao aplauso público e a fama. Eles também aprendem que possuir e consumir determinados objetos, e adotar certos estilos de vida é condição necessária para a felicidade, talvez até para a dignidade humana.

político), enquanto o segundo se liga a ideia de atrair a atenção para determinado bem ou serviço, com o fito de promover sua comercialização. A publicidade é, pois, o nome genérico do conjunto das ferramentas de comunicação de marketing, sejam elas desenvolvidas por meio de mídia massificada (televisão, rádio, jornais, revistas outdoors) ou de técnicas de abordagem direta do consumidor (marketing direto). (ERENBERG, 2003, p. 17-19). 
Observa-se que a publicidade online incentiva ${ }^{3}$ o consumo e, a sociedade em rede, por sua vez, potencializa essa indústria ávida por um mercado extremamente promissor, que movimenta milhões de dólares em todo o mundo. O bombardeio de mensagens e promessas de felicidade oferecida pelos produtos e serviços anunciados captura o consumidor, reduzindo seu poder de reflexão sobre os impactos e possíveis riscos advindos do seu uso, e assim os consumidores sequer pensam sobre qual a tecnologia foi aplicada na produção e nos possíveis efeitos colaterais decorrentes do uso contínuo dos produtos. Esse tema ganha ainda maior relevância quando os produtos são nanoestruturados.

Como visto no tópico anterior, a despeito das prometidas vantagens, ainda há grandes dúvidas científicas sobre os produtos nanoestruturados em virtude da carência de investigações que atestem, com segurança, o seu potencial ofensivo. A despeito das dúvidas, no entanto, esses produtos estão no mercado à disposição do consumidor, ofertados através de um sistema de mídia onipresente, a publicidades online.

A informação constante na publicidade online assume contornos bastante importantes, pois tanto pode incitar à compra dos produtos, como visto acima, como também tem o dever de informar corretamente os consumidores. Esse dever precisa ser observado em face da vulnerabilidade do consumidor, o que aumenta à medida que novas tecnologias são utilizadas para elaboração de novos produtos e serviços que são colocados no mercado.

Assim, a publicidade online, pautada num modelo de sociedade de espetáculo no qual as pessoas perseguem padrões de beleza e promessas de juventude eterna, incentiva e promove o uso de nanocosméticos, produtos anunciados como capazes de responder satisfatoriamente a essa demanda.

Apresenta-se como exemplo de publicidade online de produtos nano, a empresa Aneethun (ANEETHUN, 2015), ligada ao mercado da beleza, com atuação na área de produtos para cabelos. Em seu site de vendas na web oferece a "Aneethun máscara nano system restauradora 250ml, Nanocomplex, Amora Negra". Na descrição do produto constam as seguintes informações:

\section{Descrição}

\footnotetext{
3 Importante distinguir claramente as duas informações básicas contidas na mensagem publicitária: uma relacionada diretamente à divulgação da existência do produto ou serviço no mercado e suas características básicas, outra, paralela e secundária, relacionada com a alteração psíquica que se induz no destinatário da mensagem, a fim de compeli-lo ao consumo do produto ou serviço. Na primeira informação que se podem localizar as situações na quais surgirá a figura da publicidade enganosa. Na segunda, os casos de publicidade abusiva (ERENBERG, 2003, p. 20).
} 
Elaborada com nanotecnologia, esta fórmula tem alto poder restaurador. Combina ingredientes tecnológicos e hidratantes vegetais que tratam os fios de dentro para fora. Proporciona um incrível desembaraço, toque leve, sedoso e brilho intenso. Modo de Aplicação

Aplique nos cabelos molhados, massageando mecha a mecha. Para completa absorção dos ativos, deixe agir por 2 minutos. Enxágue

\section{Resultado}

Cabelos sedosos, desembaraçado e brilho intenso.

Outro exemplo de publicidade online de nanocosméticos está no site da empresa Anna Pegova (ANNA PEGOVA, 2015), que oferece o produto Akinésine gel contour des yeux, nanocosmético rico em ativos de última geração, uma verdadeira inovação para o contorno dos olhos. Segue a descrição do produto no site:

Resultado de uma pesquisa avançada sobre os mecanismos biológicos da formação das rugas, olheiras e bolsas, AKINÉSINE GEL CONTOUR DES YEUX, é um nanocosmético com toda a tecnologia dos biopeptídeos, para rejuvenescer a pele do contorno dos olhos.

AKINÉSINE GEL CONTOUR DES YEUX contém um inovador e exclusivo complexo de biopeptídeos revitalizantes, que corrigem e retardam os primeiros sinais da idade, além de terem forte ação antibolsas, antiedemas e antiolheiras.

Ação rápida e eficiente. Em apenas 30 dias a redução de rugas, olheiras, bolsas e inchaços ao redor dos olhos foi significativa, sendo de aproximadamente $90 \% *$.

Em uma primeira etapa, o produto age no preenchimento e redução da profundidade das rugas, de dentro para fora, ao mesmo tempo em que atenua as bolsas e olheiras. Ativa a microcirculação cutânea, descongestiona e drena as toxinas acumuladas, devido a má circulação, que favorece o escurecimento da região. Em seguida constata-se a eliminação de linhas finas, rugas e sinais de cansaço.

Testado dermatologicamente AKINÉSINE GEL CONTOUR DES YEUX é hipoalergênico e pode ser aplicado duas vezes ao dia (manhã e noite).

*Resultados obtidos por testes dermoclínicos após 30 dias de uso: Redução de rugas e olheiras $(90,6 \%)$ e bolsas e inchaços $(88,7 \%)$.

Conforme se observa, em nenhuma dessas mensagens publicitárias há qualquer referência ou advertência a possíveis riscos que seu uso poderá provocar na saúde do consumidor. A publicidade online somente aborda a provável eficiência dos produtos, com o intuito de induzir ao consumo, mas em momento algum informa a tecnologia utilizada na produção.

Outras empresas, além das de nanocosméticos, também se utilizam da publicidade online para vender produtos nano de toda ordem. Dentre os exemplos encontram-se os produtos oferecidos pela empresa Nanox Clean (NANOXCLEAN, 2015) que utiliza a tecnologia antimicrobiana, desenvolvida a partir do uso da nanotecnologia, gerando produtos que são destinados a mercados variados. Para ampliar o repertório, basta consultar o site 
Nanoshop.com, onde há grande variedade de produtos nano que se encontram em fase de desenvolvimento e distribuição no mercado.

Percebe-se, portanto, que o termo "nanotecnologia" tem sido cada vez mais presente nos anúncios e peças publicitárias ${ }^{4}$, pois é uma tecnologia nova e que apresenta resultados quase que imediatos. No entanto, em momento algum os fornecedores informam o que é nanotecnologia e seus possíveis riscos, o que vulnera o princípio da informação, contemplado no Código de Defesa do Consumidor brasileiro, que exige que a informação seja completa, permitindo autonomia de escolha do consumidor, sem violar direitos fundamentais.

Ao lado da publicidade online produzida pelo fabricante, a sociedade informacional ainda deu ensejo a novos atores, como os $b \log s^{5}$ e os sites com informações específicas para mulheres que fornecem informações de todo tipo, inclusive sobre beleza e as inovações e novidades dos produtos de beleza. Esses sites específicos para mulheres utilizam o ambiente virtual para anunciar suas "dicas" e conselhos de beleza e rapidamente congregam uma legião de seguidores. Muitas de suas postagens são verdadeiros anúncios publicitários, que indicam e atestam a qualidade dos produtos, o que permite afirmar que em alguns casos, estes sites, atuam como parte integrante da cadeia de fornecimento, pois ainda que não tenham o reconhecimento formal, incentivam ao consumo de produtos e "falam" em nome de um fornecedor.

Dentre os inúmeros sites existentes tem-se o Bolsa de Mulher6. Analisando as inúmeras postagens feitas nesse ambiente constatou-se que foi publicada uma reportagem intitulada "Nanocosmética - conheça a tecnologia que está revolucionando os produtos de beleza”. Essa matéria trata das inúmeras vantagens da aplicação da nanotecnologia aos cosméticos, conforme se pode verificar do seguinte trecho da publicação (BOLSA DE MULHER, 2015):

\footnotetext{
${ }^{4}$ Outras tantas grandes empresas utilizam-se da nanotecnologia em seus produtos, mas sequer informam isso aos seus consumidores em seus apelos publicitários online, somente enfatizando a eficiência e qualidade do produto. ${ }^{5}$ Blogs são "Websites frequentemente atualizados onde os conteúdos (textos, fotos, arquivos de som, etc) são postados em uma base regular e posicionados em ordem cronológica reversa. Os leitores quase sempre possuem a opção de comentar em qualquer postagem individual, que são identificados com uma URL única". (AMARAL, RACUERO; MONTARDO, 2009, p. 30).

${ }^{6} \mathrm{O}$ site Bolsa de Mulher é um dos sites do Grupo Bolsa de Mulher, propriedades digitais da empresa Batanga Media. O Grupo, hoje com 322 MM de page views e 34 MM de unique visitors*, é composto pelos sites Bolsa de Mulher, iTodas, EstrelaGuia e pela rede Pink Adnetwork, além da Sophia Mind Pesquisa e Inteligência de Mercado, focada em compreender o universo feminino por meio de pesquisas direcionadas. Os sites dialogam com a mulher através de uma linha editorial baseada em conteúdo publicados, em entrevistas com pessoas famosas e profissionais renomados, além de salientar, em seu ambiente, sua constante preocupação com a boa apuração das informações. (BOLSA DE MULHER, 2015).
} 
Estamos vislumbrando um futuro sem a necessidade de intervenções cirúrgicas ou procedimentos estéticos invasivos

No mundo existem hidratantes, tinturas de cabelo, cremes de redução de medidas, entre outros cosméticos, com nanopartículas. O mercado brasileiro já oferece opções de produtos com essa característica. Alguns deles têm ação dermorrelaxante, ou seja, se propõem a inibir a contração muscular facial e minimizar as rugas: alternativa não invasiva em comparação com a aplicação da toxina botulínica.

Chama atenção que essa mesma reportagem, ao lado das vantagens e promessas de resultados "milagrosos", também informa que se trata de uma tecnologia que ainda oferece dúvidas quanto à segurança, advertência que usualmente não aparece nos anúncios realizados diretamente pelo fornecedor, conforme é possível constatar (BOLSA DE MULHER, 2015):

Nem tudo são peles maravilhosas. Existe o outro lado da moeda. "Não se sabe ao certo se as nanosferas podem penetrar além da camada da derme e atingir a corrente sanguínea", diz a dermatologista. Se uma pessoa for alérgica a determinada substância e ela entrar mais profundamente na pele, a reação é potencializada. Mas uma coisa é certa: trata-se de uma revolução na dermatologia cosmética. "Estamos vislumbrando um futuro sem a necessidade de intervenções cirúrgicas ou procedimentos estéticos invasivos"...

Ainda que a matéria publicada tenha apenas uma rápida e pouco aprofundada advertência sobre os potenciais riscos, esse tipo de informação se constitui em exceção, pois como regra apenas são enaltecidas as propriedades positivas dessa tecnologia. No caso do site Bolsa de Mulher (2015) os seus seguidores receberam a informação e a partir dela poderão optar se querem ou não fazer uso de produtos que se utilizam da nanotecnologia.

Quer seja feita de maneira direta e ostensiva, quer se misture a outros fluxos informacionais e assuma novas formas, o objetivo da publicidade, como bem ressalta Fernandes Neto (2004, p.50), é "estimular necessidades existentes ou criar novas outras que ainda não existem". Quando essa publicidade é feita através da internet ainda tem maior penetração, pois além de se misturar a outros entretenimentos, passando despercebida pelos internautas, ainda pode alcançá-los em qualquer hora do dia ou da noite, sete dias por semana e trezentos e sessenta e cinco dias por ano.

Quando essas estratégias são confrontadas com a legislação brasileira percebe-se que muitas delas são combatidas, pois não permitem que o consumidor claramente identifique a mensagem como publicitária. Ademais, o art. 36 do Código de Defesa do Consumidor obriga o fornecedor a manter em seu poder, para informação dos legítimos interessados, os dados fáticos, técnicos e científicos que dão sustentação à mensagem, ou seja, além de informar, deve manter os dados que originaram a pesquisa e levaram o fornecedor a garantir aqueles níveis de eficiência. 
Essas exigências muitas vezes são desconsideradas e, a despeito das dúvidas quanto à segurança dos produtos nano eles estão no mercado, sendo oferecidos através de poderosas estratégias de marketing, que induzem o consumidor a se utilizar de um produto que promete resultados imediatos, sem explicações ou informações sobre possíveis riscos.

Em face do estado atual da pesquisa percebe-se que o desafio é garantir "a efetiva prevenção" do consumidor, conforme art. $6^{\circ}$, inciso VI do Código de Defesa do consumidor, especialmente frente à emergência de produtos que se utilizam da nanotecnologia lançados no mercado, atingindo diretamente o consumidor através da publicidade online.

Tal medida se faz pertinente, pois ainda que não se tenham obtido resultados precisos que garantam a segurança do consumidor e ainda que a matéria não esteja regulamentada expressamente, os consumidores estão sendo incentivados a consumir esses produtos, o que é feito principalmente através da publicidade online. O tema assume especial importância porque é responsabilidade do Estado prestar a devida tutela ao consumidor, conforme art. $5^{\circ}$, XXXII, da Constituição Federal (BRASIL, 2008).

Resta verificar, portanto, se as regras e princípios previstos no Código de Defesa do Consumidor brasileiro são adequadas e suficiente para proteger o consumidor em face da publicidade de produtos nanoestruturados realizada no ambiente virtual, tema que será desenvolvido no próximo tópico.

\section{O BRASIL E SEUS PARADOXOS: DO DESTAQUE COMO LÍDER EM NANOTECNOLOGIA À AUSÊNCIA DE REGULAÇÃO SOBRE O TEMA.}

Conforme dados do NANoREG (2014), organização europeia responsável pela regulação e comercialização de nanomateriais, o Brasil é líder em nanotecnologia na América Latina. Entretanto, o governo brasileiro ainda não desenvolveu um regime de regulamentação que leve em conta os aspectos relativos à nanotecnologia e seus impactos sociais, no meio ambiente, aos consumidores destinatários da publicidade online e até com o próprio trabalhador da indústria que manipula nanopartículas em sua produção.

As vantagens desses produtos (evidenciadas no item 2.1) somadas à lacuna legislativa têm contribuído para a proliferação de grandes fluxos de publicidade online de produtos contendo aditivos em nanoescala. Ávidos por desfrutar das últimas novidades do mercado de consumo, muitas pessoas se utilizam desses produtos sem ter informações suficientes sobre sua forma de ação sobre o corpo, ignorando o fato de seus condutores 
quebrarem algumas barreiras da pele e atingirem diretamente a corrente sanguínea, potencializando riscos, inclusive de se acumularem em diversos órgãos.

Ainda que potenciais, os estudos e pesquisas até então realizados mostram-se insuficientes para estabelecer a toxicidade e mobilidade dessas partículas no corpo humano, sobretudo na pele, no fígado e na placenta humana. Apesar desse quadro de incerteza acerca da toxicidade, a indústria faz uso da publicidade, com destaque para as mensagens veiculadas no ambiente virtual, para divulgar um número crescente de produtos.

Esse fato é agravado em razão da inexistência de um sistema de regulamentação jurídica com diretrizes específicas referentes à comercialização e publicidade online desses produtos. Sequer a Agência Nacional de Vigilância Sanitária (ANVISA, 2011), cujos objetivos e finalidades institucionais visam a "[...] promover a proteção da saúde da população por intermédio do controle sanitário da produção e da comercialização de produtos e serviços submetidos à vigilância sanitária, inclusive dos ambientes, dos processos, dos insumos e das tecnologias a eles relacionados" dispõe de qualquer regra ou ação sobre o tema.

E apesar de o Brasil ser líder desse segmento na América Latina, recém em 21 de agosto de 2014 foi instituído o Comitê Interno de Nanotecnologia da Anvisa. Entre as atribuições do Comitê, está a elaboração de normas ou guias específicos para a avaliação e controle de produtos que utilizam nanotecnologia. A Portaria que instituiu o Comitê também prevê a criação de um banco de dados sobre nanopartículas ou nanomateriais relacionados à saúde e a elaboração de um plano de capacitação, entre outras atribuições (ANVISA, 2014).

Importante ressaltar, que no inciso XII, do artigo $2^{\mathrm{a}}$ da Portaria 1.358/14, trata de formular proposta de cooperação com agências congêneres sobre estratégias regulatórias e de avaliação de risco de produtos nanotecnológicos. Ou seja, se admitem possíveis riscos por conta do uso da nanotecnologia, entretanto a Portaria não apresenta nenhuma ação quanto aos produtos que já estão no mercado sendo oferecidos diretamente ao consumidor através da publicidade online.

Outro ponto que chama atenção é o fato de a ANVISA analisar os riscos dos produtos cosméticos aplicando parâmetros sobre condições de uso, composição do produto e seu histórico (ANVISA, 2003 apud FRONZA; GUTERRES; POHLMANN; TEIXEIRA, 2007, p.37):

- Condições de uso: categoria e proposta de uso do produto, modo de uso, quantidade de produto a ser utilizada a cada aplicação, frequência de uso do produto, duração do contato, área e superfície de aplicação, público alvo e advertências e restrições de uso. 
- Composição do produto: fórmula qualitativa, concentração dos ingredientes, dados toxicológicos dos ingredientes, existência de restrições e/ou regulação específica para alguns ingredientes, possíveis interações entre os ingredientes, observação de margem de segurança para os ingredientes considerados mais críticos.

- Histórico e conhecimento do produto: dados referentes ao produto e a produtos semelhantes (experimentais, bancos de dados ou de literatura) (ANVISA, 2003 apud FRONZA; GUTERRES; POHLMANN; TEIXEIRA, 2007, p.37).

Ora, se os riscos sistêmicos dos cosméticos são avaliados a partir de dados relativos às matérias-primas, o consumidor necessita ser minimamente informado sobre isso, pois cabe a ele fazer uso de sua autonomia para decidir se quer se submeter a esses riscos.

Nesse sentido cabe lembrar que o Estado brasileiro assumiu o compromisso, no texto da Constituição Federal (art. 5, XXXII) de promover a defesa do consumidor editando, para tanto, o Código de Defesa do Consumidor (CDC), uma das mais modernas legislações consumeristas do mundo.

E é exatamente essa legislação que obriga o Estado a atuar, pois o art. $4^{\circ}$ evidencia a imposição da "presença do Estado no mercado"; enquanto os arts. $6^{\circ}$, VI e $7^{\circ}$ apresentam o princípio da prevenção de danos individuais e coletivos, morais e materiais aos consumidores. O cumprimento desses deveres fica claramente prejudicados quando analisado o cenário brasileiro e o grande consumo de nanocosméticos sem qualquer advertência ou ação do Estado sobre esse mercado. Essa ausência de atuação estatal fragiliza a saúde e a segurança do consumidor, compromissos também assumidos no art. $8^{\circ}$, do CDC.

Ao estudar esse dispositivo, Claudia Lima Marques, Antonio Herman Benjamin e Bruno Miragem (2010, p.352) explicam que o CDC impõe uma "teoria da qualidade", segundo a qual "os produtos e serviços colocados no mercado pelos fornecedores deverão ter uma "qualidade-segurança" ( $\operatorname{art} 8^{\circ}$ a 17) e uma "qualidade-adequação" (art.18 a 25). Assim, no entendimento dos autores esse dispositivo impõe "deveres próprios e a solidariedade entre fornecedores, contratantes ou não, e em relação a todos os consumidores" (2010, p.352). Percebe-se sua forte conexão com o princípio da boa-fé objetiva e a consequente responsabilidade civil objetiva que emerge em casos de danos, o que se alicerça sobre o "risco de empresa", previsto no art.927, parágrafo único, do Código Civil de 2002 e no art. $8^{\circ}$ do CDC.Trata-se de uma garantia implícita de segurança e de adequação, que inclui a falha informacional como defeito ou vício do produto ou serviço.

Como se vê, esses autores destacam o papel fundamental da informação, que deveria constar, também, na publicidade online. E não poderia ser diferente, já que é a partir dela que o consumidor poderá, valendo-se de sua autonomia, optar por expor-se ou não a produtos com essa nova tecnologia.

Revista de Direito, Glob e Res. nas Rel. de Cons.| e-ISSN: 2526-0030 | Minas Gerais | v. 1 | n. 2 | p. 1-26|Jul/Dez. 2015. 
Como afirmam Marques, Benjamin e Miragem (2010, p. 247) quando o consumidor recebe a informação e exerce sua livre escolha quanto aos produtos que quer consumir efetivam-se e preservam-se valores elencados constitucionalmente, quais sejam, a dignidade da pessoa humana (art.1 ${ }^{\circ}$, III), direito à vida (art. $5^{\circ}$, caput), direito à liberdade e à informação (art. $5^{\circ}$, caput e XIV), efetivando-se a proteção dos direitos do consumidor (art. $5^{\circ}$, XXXII). Nessa mesma esteira protege-se o direito de escolha, elencado no art. $6^{\circ}$, II, do CDC. Esses direitos devem ser respeitados, pois foram erigidos a princípios basilares que inspiram e orientam o tratamento do consumidor.

O inciso III, do art. $6^{\circ}$ do Código de Defesa do Consumidor, dispõe que o consumidor tem como direito básico, "a informação adequada e clara sobre os diferentes produtos e serviços, com especificação correta de quantidade, características, composição, qualidade e preço, bem como sobre os riscos que apresentem" e, conforme demonstrado na parte inicial deste trabalho, a publicidade online não atende a esse requisito, pois em geral não há advertências sobre os eventuais riscos.

Ao fornecedor é imposta uma obrigação de informar positivamente o consumidor, conforme o art. 31 do CDC que, devido a sua importância, será transcrito abaixo:

Art. 31. A oferta e apresentação de produtos ou serviços devem assegurar informações corretas, claras, precisas, ostensivas e em língua portuguesa sobre suas características, qualidades, quantidade, composição, preço, garantia, prazos de validade e origem, entre outros dados, bem como sobre os riscos que apresentam à saúde e segurança dos consumidores.

Parágrafo único - As informações de que trata este artigo, nos produtos refrigerados oferecidos ao consumidor, serão gravadas de forma indelével.

Para cumprir este comando legal a indústria pode se utilizar de ferramentas como o rótulo dos produtos, embalagens, impressos e mesmo a publicidade online para informar corretamente o consumidor. Assim, da mesma forma que a publicidade online é intensamente utilizada para difundir novos produtos e serviços, também deve informar sobre eventuais riscos, pois não é o fato de ser veiculada no ambiente virtual que a retira da órbita de incidência do Código de Defesa do Consumidor.

A importância do assunto determinou a apresentação do Projeto de Lei - PL 5133/2013 ${ }^{7}$, do Sr. Sarney Filho, atualmente em tramitação na Câmara de Deputados e que visa regulamentar a rotulagem de produtos da nanotecnologia. $\mathrm{O}$ art. $2^{\circ}$ do referido projeto,

7 Ementa: Regulamenta a rotulagem de produtos da nanotecnologia e de produtos que fazem uso da nanotecnologia (BRASIL, 2015). 
refere-se ao dever de informar o consumidor sobre o produto, conforme transcrição (BRASIL, 2013):

Art. $2^{\circ} \mathrm{Na}$ comercialização de produto ou subproduto da nanotecnologia, que contenha, ou seja produzido a partir da manipulação nanotecnológica, o consumidor deverá ser informado sobre o produto.

$\S 1^{\circ}$ Tanto nos produtos embalados como nos comercializados a granel ou in natura, no rótulo da embalagem ou do recipiente em que estão contidos deverá constar, em destaque, uma das seguintes expressões, dependendo do caso: "(nome do produto) obtido por processo nanotecnológico ", "contém (nome do ingrediente ou ingredientes) nanotecnológico (s)" ou " produzido a partir de processo de nanotecnologia".

$\S 2^{\circ}$ as expressões citadas no $\S 1^{\circ}$ deste artigo devem estar no painel principal e em conjunto com o símbolo que identifica a presença de produto ou processo nanotecnológico, definido no regulamento desta lei.

$\S 3^{\circ}$ No caso de cosméticos, alimentos e fármacos, o consumidor deverá ser informado sobre a matéria-prima nanotecnológica utilizada.

$\S 4^{\circ} \mathrm{A}$ informação determinada no $\S 1^{\circ}$ deste artigo também deverá constar do documento fiscal de modo que essa informação acompanhe o produto ou ingrediente em todas as etapas da cadeia produtiva.

Interessante observar que este Projeto de Lei nada refere quanto aos produtos que já estão sendo ofertados aos consumidores através de publicidade online, cujas mensagens que ressaltam somente a eficiência e os resultados imediatos.

E aqui se apresenta um dos aspectos mais importantes desse tema e que vai além da regulamentação. $\mathrm{O}$ atual quadro normativo brasileiro já oferece alguma proteção ao consumidor, impondo o dever de informar sobre os riscos dos produtos e serviços. A vulnerabilidade técnica e informacional é amplamente reconhecida na doutrina ${ }^{8}$ e a publicidade contém regras já consolidadas, especialmente nos artigos $36{ }^{9}$ e seguintes do CDC. É inegável que essa proteção ficará ainda mais completa se efetivamente o Brasil contar com legislação específica sobre produtos nanoestruturados, cuja necessidade e importância são indiscutíveis. No entanto, essas medidas talvez não cumpram os objetivos esperados, pois a despeito de o CDC obrigar o fornecedor a informar a composição dos

8 Nas lições de Marques, Benjamin e Miragem (2010, p.197), a igualdade deve ser vista não como uma visão macro do homem e da sociedade, não como uma noção mais objetiva e consolidada em que a desigualdade se aprecia pela comparação de situações e pessoas, tratando os iguais igualmente e os desiguais desigualmente para se obter a justiça. Conforme esses autores, a vulnerabilidade deve ser vista com uma noção mais flexível e não consolidada, apresentando traços de subjetividade como característica e não necessitando sempre de uma comparação entre situações e sujeitos. Sendo assim, a vulnerabilidade é um estado da pessoa, um estado inerente de risco ou um sinal de confrontação excessiva de interesses que fragiliza o sujeito de direitos, desequilibrando a relação de consumo.

${ }^{9}$ Art. 36. A publicidade deve ser veiculada de tal forma que o consumidor, fácil e imediatamente, a identifique como tal. Parágrafo único. O fornecedor, na publicidade de seus produtos ou serviços, manterá, em seu poder, para informação dos legítimos interessados, os dados fáticos, técnicos e científicos que dão sustentação à mensagem. 
produtos e eventuais riscos advindos de determinado produto, quando as mensagens são publicadas no ambiente virtual elas facilmente escapam à fiscalização ou filtragem dos conteúdos.

Portanto, mesmo que venha a ser editada a legislação específica sobre os produtos nanoestruturados, a rapidez dos fluxos mais uma vez superará o tempo da legislação e permitirá que a publicidade online continue a chegar instantaneamente ao consumidor, propagando promessas de bem viver, enquanto oculta os eventuais riscos e impactos que essa tecnologia pode oferecer.

Esses limites e a ausência de qualquer regulação da publicidade online impõem que se lance um olhar para as práticas empreendidas em outras partes do mundo, a exemplo da União Europeia, que há anos já percebeu esse promissor mercado. Cabe saber se ao lado do interesse econômico há preocupação legal com a saúde e segurança do consumidor, podendose afirmar a existência de um mínimo de regulação sobre o setor, tema que será evidenciado no próximo tópico.

\section{O TRATAMENTO JURÍDICO DA NANOTECNOLOGIA NA UNIÃO EUROPEIA.}

A União Europeia, conforme Regulamento (UE) $n^{\circ} 1291 / 2013^{10}$, manifesta grande interesse nas pesquisas e inovações em nanotecnologias, já que tem por objetivo garantir a liderança neste mercado global em elevado crescimento. Nesse intento, tem incentivando os avanços científicos e tecnológicos e o investimento em nanotecnologias, assim como a sua aceitação em produtos e serviços, agregando valor e tornando-os competitivos e amplamente aplicáveis e vários setores da indústria (UNIÃO EUROPEIA, 2015).

Segundo se verifica a partir do referido documento, emitido pelo Parlamento Europeu e pelo Conselho da União Europeia em 11 de dezembro de 2013, a União Europeia pretende assumir a liderança mundial na área de nanotecnologia e para isso estabelece metas que devem ser cumpridas até o ano de 2020 (UNIÃO EUROPEIA, 2015), o que também envolve a regulamentação do tema:

O objetivo específico da investigação e inovação em nanotecnologias é garantir a liderança da União neste mercado global em elevado crescimento, incentivando os avanços científicos e tecnológicos e o investimento em

10 REGULAMENTO (UE) No.1291/2013 DO PARLAMENTO EUROPEU E DO CONSELHO, de 11 de dezembro de 2013, que cria o Horizonte 2020 - Programa-Quadro de Investigação e Inovação (2014-2020) e que revoga a Decisão n'.1982/2006/CE (UNIÃO EUROPEIA, 2015). 
nanotecnologias e a sua aceitação em produtos e serviços de elevado valor acrescentado e competitivos numa vasta gama de aplicações e setores.

Até 2020, as nanotecnologias estarão generalizadas, ou seja, integradas sem descontinuidades na maioria das tecnologias e aplicações, orientadas para beneficiar os consumidores, a qualidade de vida, os cuidados de saúde, o desenvolvimento sustentável e o forte potencial industrial para atingir soluções de que não se dispunha anteriormente para a produtividade e a eficiência na utilização dos recursos.

A Europa deve também definir o parâmetro de referência global em matéria de implantação e governação segura e responsável das nanotecnologias, assegurando não só elevados benefícios a nível industrial e societal como também elevadas normas de segurança e sustentabilidade.

Os produtos que utilizam nanotecnologias representam um mercado mundial que a Europa não se pode permitir ignorar. As estimativas relativas ao valor do mercado de produtos que incorporam nanotecnologias como componente-chave apontam para 700 mil milhões de EUR até 2015 e 2 biliões de EUR até 2020, com um número correspondente de 2 e 6 milhões de postos de trabalho, respetivamente. As empresas da Europa no domínio das nanotecnologias devem tirar partido deste crescimento do mercado de dois dígitos e ser capazes de captar uma quota de mercado pelo menos igual à quota-parte da Europa no financiamento da investigação a nível mundial (ou seja, um quarto) até 2020.

Assim sendo, pode-se observar no Regulamento (UE) n 1291/2013 do Parlamento Europeu e do Conselho da União Europeia é formalmente reconhecido que as nanotecnologias têm um papel "crucial a desempenhar" no plano de ações na Estratégia Europa 2020.

Com vista a concretizar tais intentos, a UE vem investindo alto no financiamento de pesquisas em nanotecnologias, o que a coloca em posição de reconhecida liderança na investigação no domínio das nanociências e nanotecnologias, com projeção de cerca de 4000 empresas na UE até 2015. Essa liderança nas pesquisas deve ser mantida e ampliada, pois será utilizada na prática e na comercialização, assegurando e consolidando a posição da UE no mercado global (UNIÃO EUROPEIA, 2015).

Da leitura do referido documento depreende-se que ao lado do reconhecimento das potencialidades para o desenvolvimento econômico e consolidação das empresas europeias também há a preocupação com a "governança" segura e sustentável dessa tecnologia, o que por certo exigirá a edição de regulação compatível com o tema. Toda essa construção, no entanto, ainda está por vir e, enquanto isso, a produção, difusão e consumo desses produtos são realidade.

Conforme se verifica da leitura do item 1.2.3, "b" do regulamento, constata-se que um dos objetivos da União Europeia nesse segmento é (UNIÃO EUROPEIA, 2015) é:

b) Garantir o desenvolvimento e aplicação das nanotecnologias em condições de segurança e sustentabilidade 


\begin{abstract}
Permitir avanços nos conhecimentos científicos sobre o potencial impacto das nanotecnologias e dos nanossistemas na saúde ou no ambiente e disponibilizar ferramentas para a avaliação e gestão dos riscos ao longo de todo o ciclo de vida, incluindo questões de normalização.
\end{abstract}

A explicação que acompanha o item "b" evidencia que ainda não há precisão sobre os impactos que a nanotecnologia acarreta para a saúde dos consumidores e o meio ambiente, sendo necessário que ao lado da expansão das empresas também ocorra o aprofundamento das pesquisas para que se atinja melhor delimitação dos riscos.

E nesse caso fica bem evidente que os interesses econômicos ditam o ritmo das ações, pois antes mesmo que se delimitarem os riscos são feitos investimentos de grande porte, anunciados, vendidos e consumidos tais produtos, sem grandes considerações pela saúde do consumidor.

Cabe ainda referir que a nova Diretiva de Direitos dos Consumidores da UE, de 13 de junho de 2014, aplicável em todos os Estados-Membros, visa reforçar os direitos dos consumidores e alcançar o equilíbrio entre a defesa do consumidor e a competitividade das empresas. Ainda que a legislação em matéria de consumo e comercialização tenha por objetivo proteger os interesses econômicos dos consumidores abrangendo, sobretudo, as práticas comerciais ilegais e o direito dos contratos de consumo (nomeadamente a publicidade enganosa e as cláusulas contratuais abusivas), nada refere sobre produtos com nanotecnologia, sua comercialização e publicidade online (UNIÃO EUROPEIA, 2015).

Analisando os documentos produzidos pelo bloco, constata-se que desde o ano de 2005 a União Europeia proíbe determinadas técnicas de venda que configuram publicidade enganosa, bem como certas práticas comerciais desleais ou agressivas. Portanto, não admite haver custos ocultos, truques, alegações falsas, informações errôneas e publicidade dirigida às crianças.

No que se refere aos cosméticos, o Regulamento n 655/2013 da Comissão Europeia, de 10 de julho de 2013, estabelece critérios comuns para justificação das alegações relativas a esses produtos, o que é exigido para evitar que os fabricantes façam publicidade se utilizando de informações enganosas. A partir dessas novas regras, frases como "hidratação durante 48 horas" só podem surgir na embalagem de um creme se respeitarem 6 critérios: tomada de decisão informada, conformidade legal, veracidade, sustentação de prova, honestidade e imparcialidade. Tais regras aplicam-se aos produtos colocados à venda na Europa, tanto aos fabricados na UE, como aos importados. Outra mudança a partir desse regulamento e que 
interessa diretamente a este estudo é que os nanomateriais devem constar na lista de ingredientes, através da palavra "nano" entre parênteses, depois do nome da substância ${ }^{11}$.

Na esteira desses esforços da UE, pode-se mencionar a criação da NaNoREG (2015).

Por esta iniciativa a organização europeia responsável pela regulação e comercialização de nanomateriais tem feito aproximações com o Brasil, através do Ministério da Ciência, Tecnologia e Inovação (MCTI), com vistas à criação de uma regularização mundial, e não apenas regional, para a comercialização dos produtos nano. O interesse no Brasil se deve ao fato de o país ser um dos líderes em pesquisas em nanotecnologia na América Latina (UNIÃO EUROPEIA, 2015).

Tal iniciativa adotada no ano de 2014 evidencia que a UE, a despeito do interesse nas pesquisas em decorrência do grande potencial econômico que tais produtos oferecem, ainda não dispõe de regulamentação para pesquisa, para a publicidade online e comercialização desses produtos. Tal quadro, típico de uma sociedade de risco $^{12}$, evidencia uma triste realidade: primeiro são feitos investimentos em setores econômicos estratégicos pensando em alavancar vendas, ampliar postos de trabalho e desenvolver mercados para, em um segundo plano, investigar e precisar possíveis riscos advindos da manipulação e consumo de tais produtos.

\section{CONSIDERAÇÕES FINAIS}

O desenvolvimento tecnológico experimentado nos últimos anos causou profundas transformações sociais e econômicas, colocando no mercado novos produtos e serviços com destaque, neste artigo, para os produtos nanoestruturados.

Apesar das inúmeras promessas de vantagens ao consumidor, o fato é que essa nova tecnologia, que é capaz de reduzir os componentes a escolas muito pequenas também oferece alguns riscos à saúde e segurança do consumidor, sobretudo pela possibilidade de produzir acúmulos de partículas em alguns órgãos humanos, o que no mínimo suscita algumas interrogantes sobre os riscos do seu consumo.

\footnotetext{
${ }^{11}$ Apesar de haver regras gerais sobre a obrigatoriedade da identificação que se trata de produto "nano", nada se menciona quanto à publicidade online de produtos que se utilizam da nanotecnologia que, como se sabe, tem mais penetração junto aos consumidores, além de se evadir dos sistemas de fiscalização ou filtragem de conteúdos.

12 Para Varella (2005, p. 13), “À medida que a sociedade industrial, baseada na ciência, tecnologia e investimento financeiro, desenvolveu-se, novos riscos apareceram". O risco, então, é inerente a toda ideologia do Estado moderno, que foi construído sobre a base do medo, do caos e no chamado "Estado de bem-estar" (VARELLA, 2005, p. 11).
} 
Não obstante a ausência de certezas científicas, o fato é que esses produtos são produzidos e anunciados aos consumidores sem a necessária e clara informação sobre os componentes que possuem, restando igualmente ignorado o dever de informar sobre qualquer risco. Tais práticas são recorrentes na publicidade em geral, ganhando destaque e ainda maior dificuldade para seu enfrentamento quando se apresentam na publicidade online. Nesse sentido o artigo evidenciou que os anúncios na internet são usuais, ostentando mensagens que encorajam o consumo, como visto no caso dos nanocosméticos.

As promessas de resultados eficientes e instantâneos não são acompanhadas, no entanto, das necessárias advertências sobre os potenciais riscos à saúde e segurança do consumidor, o que afronta a proteção estabelecida pelo Código de Defesa do Consumidor.

A publicidade online de produtos nanoestruturados, em especial aquela de cosméticos, faz uma legião de seguidores e não se leva em conta o direito à informação e a vulnerabilidade do consumidor, princípios que devem ser observados pelo fornecedor, assim como os princípios da confiança e boa-fé, norteadores de toda a relação de consumo.

Em que pese a ofensa a vários desses princípios e o compromisso assumido pelo Brasil em harmonizar os interesses do mercado com a tutela do consumidor, o Estado brasileiro está inerte, assim como seus órgãos de fiscalização, pois a ANVISA não apresenta nenhuma atuação de proteção ao consumidor frente aos produtos que se utilizam da nanotecnologia, já disponíveis no mercado. O Ministério Público, outra importante instituição que tem a incumbência de tutelar o consumidor, tampouco agiu no interesse da coletividade. Enquanto isso produtos são ofertados online, suas potencialidades são enaltecidas para fomentar o uso desenfreado, que enriquecerá ainda mais a indústria desse segmento, sem que sequer as advertências sejam feitas para que o consumidor possa exercer sua autonomia de escolha.

Essa situação não é exclusiva do Brasil, pois ao longo do artigo ficou demonstrado que a União Europeia, a despeito de demonstrar grande interesse em pesquisas e na comercialização de produtos nanoestruturados não dispõe de mecanismos para regular a pesquisa, a publicidade online e a comercialização desses produtos.

De tudo o que foi pesquisado conclui-se que tanto o Brasil como a UE são sabedores dos benefícios econômicos que a nanotecnologia pode oferecer, movimentando a economia e agregando valor aos produtos. No entanto, os passos no sentido do tratamento dos riscos são quase inexistentes, encontrando-se como exemplo apenas a criação da NANOREG, no ano de 2014. Se por um lado constata-se uma incipiente aproximação do Brasil com aquele bloco e a 
convergência de preocupações em comum quanto ao quesito segurança, também é claramente perceptível que o interesse econômico prevalece e é ele que ditará o ritmo e o modelo de qualquer regulação.

A preocupação com essa temática revelou-se plenamente justificada, pois não se deve levar em conta somente os ganhos financeiros proporcionados por essa nova tecnologia, em detrimento da saúde e da segurança dos consumidores.

A efetiva tutela do consumidor deve sempre considerar o princípio da informação, que deve ser clara, precisa, completa e compreensível, pois só assim será possível ao adquirente do produto nanoestruturado exercer o seu direito de livre escolha. Enquanto a publicidade online não respeitar esses parâmetros o consumidor será desrespeitado, fato que precisa ser denunciado pela academia.

\section{REFERÊNCIAS}

ANVISA. AGENCIA NACIONAL DE VIGILÂNCIA SANITÁRIA. Disponível em: < http://portal.anvisa.gov.br/wps/content/anvisa+portal/anvisa/sala+de+imprensa/menu++noticias+anos/2014+noticias/instituido+comite+interno+de+nanotecnologia+da+anvisa > Acesso em: 19 jan. 2015.

ALVES, Oswaldo. Cartilha sobre Nanotecnologia. Brasília: ABDI. Agência Brasileira de Desenvolvimento Industrial, 2010.

AMARAL, Adriana; RECUERO, Raquel; MONTARDO, Sandra. Blogs.com: estudos sobre blogs e comunicação. São Paulo: Momento Editorial, 2009.

ANNA PEGOVA. Disponível em: <http://www.annapegova.com.br/akinesine-gelcontour/s301101> Acesso em 22 jan 2015.

BAUMAN, Zygmunt. O Mal-Estar da Pós-Modernidade. Traduzido por Mauro Gama, Cláudia Martinelli Gama. Rio de Janeiro: Jorge Zahar Editor LTDA, 1998.

. Globalização: As consequências humanas. Traduzido por Marcus Penchel. Rio de Janeiro: Jorge Zahar Editor LTDA, 1999.

BENJAMIN, Antônio Herman V. MARQUES, Claudia L.; BESSA, Leonardo Roscoe. Manual de Direito do Consumidor. $2^{\text {a }}$ tiragem. São Paulo: Revista dos Tribunais, 2008.

BOLSA DE MULHER. Disponível em:

<http://www.bolsademulher.com/beleza/nanocosmetica> Acesso em 22 jan 2015. 
BRASIL. Código de Defesa do Consumidor. Lei 8.088 de 11 de setembro de 1990. Dispõe sobre a proteção do consumidor e dá outras providências. Disponível em:<

http://www.planalto.gov.br/ccivil_03/Leis/L8078.htm> Acesso em: 10 mai. 2015.

_. Constituição (1988). Constituição da República Federativa do Brasil: promulgada em 5 de outubro de 1988. Organização do texto: Yussef Said Cahali. 10. Ed. São Paulo: Revista dos Tribunais LTDA, 2008.

. Câmara dos Deputados. Projeto de Lei - PL 5133/2013. Disponível em: < http://www.camara.gov.br/proposicoesWeb/prop_mostrarintegra;jsessionid=8CB218F9D53D D4BDDACA81B8E8B01C44.proposicoesWeb2?codteor $=1064788 \&$ filename $=$ PL+5133/201 3> Acesso em: 18 feb. 2015

CASTELLS, Manuel. A sociedade em rede. A era da informação: economia, sociedade e

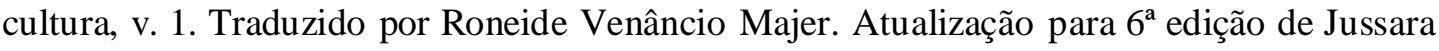
Simões. São Paulo: Editora Paz e Terra S/A, 1999.

DIAS, Lucia Ancona Lopez de Magalhães. Publicidade e Direito. São Paulo: Editora Revista dos Tribunais LTDA, 2010.

DURAN, N.; MATTOSO, L. H. C.; DE MORAIS, P. C. Nanotecnologia: introdução, preparação e caracterização de nanomateriais e exemplos de aplicação. São Paulo: Artliber Editora, 2006.

ENGELMANN, Wilson. Os direitos humanos e as nanotecnologias: em busca de marcos regulatórios. São Leopoldo: Cadernos IHU Idéias (UNISINOS), v. 123, p. 1-24, 2009-b.

ERENBERG, Jean Jacques. Publicidade Patológica na Internet. À Luz da Legislação Brasileira. São Paulo: Editora Juarez de Oliveira, 2003.

FRONZA, Tassiana. et al. Nanocosméticos. Em Direção ao Estabelecimento de Marcos Regulatórios. Porto Alegre: Gráfica da UFRGS, 2007.

FERNANDES NETO, Guilherme. Direito da Comunicação Social. São Paulo: Editora Revista dos Tribunais LTDA, 2004.

GRUPO ETC (Action Group on Erosion Technology and Concentration). Nanotecnologia: os riscos da tecnologia do futuro. Traduzido por José F. Pedroso e Flávio Borghetti. Porto Alegre: L\&PM Editores, 2005. 
INSTITUTO DE FÍSICA DE SÃO CARLOS (IFSC/USP). Comissão da União Europeia e secretário do MCTI visitam IFSC. Disponível em:

$<$ http://www.ifsc.usp.br/index.php?option=com_content $\&$ view=article \&id=2723: comissaodauniao-europeia-e-secretario-do-mcti-visitam-grupo-de-pesquisa-do-

ifsc\&catid=3:ifschoje \&Itemid=281> Acesso em: 18 oct.2014.

MARQUES, Cláudia Lima. Contratos no código de defesa do consumidor. São Paulo: Revista dos Tribunais, 1999.

NALINI, José Renato. Ética Geral e Profissional. São Paulo: Revista dos Tribunais LTDA, 2009.

NANOX INTELLIGENT MATERIALS - Nanox® Tecnologia S. A. Disponível em: <http://www.nanoxclean.com.br/> Acesso em: 16 oct. 2014.

NANOREG. Disponível em: < http://www.nanoreg.eu/> Acesso em: 16 feb. 2015.

UNIÃO EUROPEIA. Parlamento Europeu e Conselho da União Europeia. Regulamento (UE) N.o 1291/2013 do Parlamento Europeu e do Conselho. União Europeia. Disponível em: $<$ http://eur-

lex.europa.eu/legalcontent/PT/TXT/?qid=1413486560813\&uri=CELEX:32013R1291>

Acesso em: 16 feb. 2015.

UNIÃO EUROPEIA. Parlamento Europeu e Conselho da União Europeia. Regulamento (UE) N.o 655/2013 do Parlamento Europeu e do Conselho. União Europeia. Disponível em: http://eur-lex.europa.eu/LexUriServ/LexUriServ.do?uri=OJ:L:2013:190:0031:0034:PT:PDF Acesso em: 16 feb. 2015. 